\title{
Branding higher education: an exploration of the role of internal branding on middle management in a university rebrand
}

\author{
Paul Clark $^{1} \cdot$ Chris Chapleo $^{2} \cdot$ Kati Suomi $^{3}$ D
}

Received: 6 June 2019 / Accepted: 5 November 2019 /Published online: 28 November 2019

(C) The Author(s) 2019

\begin{abstract}
Although research on branding in higher education has grown, a specific focus on internal branding in this sector is still scarce. Brand support by mid-level administrative staff and deans is a key element in internal branding of a university. This study explores the extent to which internal branding contributes to this group's understanding of and engagement with a public institution's rebranding campaign. It identifies challenges and practice insights for practice for internal branding activities when engaging these internal stakeholders, linking to wider brand management theory and practice. A qualitative case study approach was employed to understand the effectiveness of internal branding holistically, and in context. In 2016, nineteen depth interviews were conducted with a range of midlevel administrators and deans including those at the student union, regional campuses, directors of departments, and deans of faculties and schools at a large Canadian university. The data was analysed using Nvivo qualitative data analysis software. On the basis of the results, it is apparent that internal branding has a valuable role in relation to higher education brand management strategy. Results offer a holistic view of the rebranding process, and explore understanding of and engagement with the rebranding campaign. This paper addresses a gap in the public sector brand management literature and demonstrates theoretical and practical implications for improved understanding and brand management strategy.
\end{abstract}

Keywords Public sector branding · Internal branding · University branding · Rebranding · Higher education $\cdot$ Knowledge-intensive organisations

Kati Suomi

kati.suomi@utu.fi

1 Thompson Rivers University, Kamloops, BC, Canada

2 Bournemouth University, Poole, UK

3 Turku School of Economics, University of Turku, Pori Unit, PL 170, 28101 Pori, Finland 


\section{Introduction}

As many countries move towards a progressively marketised higher education sector, branding has been increasingly adopted as a strategy to distinguish a university from its competitors. However, the complexity and particular characteristics of higher education make branding more challenging than in traditional commercial contexts (Chapleo and Simms 2010; Dholakia and Acciardo 2014). Research suggests that the importance of higher education brand management increases in circumstances such as this (e.g., Suomi 2014), as there is a need to succinctly articulate the essence of the institution in an increasingly competitive market and to communicate signals of quality (Balaji et al. 2016).

Branding in higher education has therefore been identified as a crucial area of future brand theory and practice (Melewar and Nguyen 2014), and there is a growing body of research on the subject. For example, Chapleo and Clark (2016) explored how a branding committee was used to facilitate a university's branding process, and Dean et al. (2016) explored how personnel co-create brand meaning via their experiences and social interactions in the university context. In the current study we refer to internal branding as "the activities undertaken by an organisation to ensure that the brand promise reflecting the espoused brand values that set customers' expectations is enacted and delivered by employees (Punjaisri and Wilson 2011, p. 1523)" .

In their recent study, Sujchaphong et al. (2014) highlight employee brand support as a key element in effective activities of internal branding within a university, and Whisman (2009, p. 367) considers internal branding as "a university's most valuable intangible asset". Indeed, Chapleo (2010) suggests that internal brand management is particularly important in universities where employees are key actors in delivering brand values because of the highly personal contact with students within a typically long educational experience (Woodall et al. 2014).

Prior studies have discussed the benefits of internal branding in the university context (e.g. Whisman 2009; Sujchaphong et al. 2014; Dean et al. 2016). However, our literature review reveals that detailed knowledge of the university branding on university middle management remains largely neglected in higher education branding literature, although it is crucial to accomplish brand 'buy in' in this important stakeholder group (see also Kuoppakangas et al. 2019). Accordingly, this study contributes to existing theoretical and practical implications by focusing on university administrators and deans to explore a university's rebranding process. This group shape the narrative and act as information conduits, hence their selection as a sample (as explored more fully in the methodology). This study therefore addresses the following research objectives:

1. To explore the extent to which internal branding contributes to mid-level administrators' and deans' understanding of and engagement with a public institution's rebranding campaign.

2. To identify challenges for internal branding activities when engaging this managerial level of internal stakeholders

3. To identify particularly beneficial practices for internal branding activities for this managerial level.

4. To explore the implications of a higher education institution's internal brand management processes for brand management theory and practice.

Because literature on the area has been criticized for covering only one or a few stakeholder groups' views on university brands (Suomi 2015), the current study covers views of 
representatives across multiple areas within the university, including representatives of the student union, directors of regional centres, directors of departments, as well as deans of faculties and schools. This study therefore offers a more holistic view of the rebranding process across this administrative level.

\section{Theoretical background}

\section{Internal branding}

The marketing literature shows consensus that marketing needs to start from the inside out (e.g. de Chernatony 2001). Internal branding has its roots in internal marketing, which rests on the idea of the employee as a customer (Rafiq and Ahmed 1993; Saleem and Iglesias 2016). The concept of internal branding is also closely linked, yet distinct, from that of employer branding (e.g., Saleem and Iglesias 2016). Internal branding is important as the branding literature shows that too often brand building efforts has been limited to "quick-fix" solutions logo redesigns and catchy slogans (Whisman 2009), however designing visible elements such as logos, slogans and colours (e.g. de Chernatony and Dall'Olmo Riley 1998), is only a part of successful brand building. Indeed, internal branding should precede design of tangible brand elements and external branding, whose goal is to represent a compelling "purchase value proposition" to potential and current customers (Simmons 2009, pp. 686-687; see also Vallaster and de Chernatony 2006; Davies 2008; Hytti et al. 2015). Internal branding is imperative in enhancing employees' attachment and identification with the brand, as well as in managing employees' awareness and perceptions of the brand (Sullivan 2004; Foster et al. 2010). Regarding identification, Ind (2001) suggests that employers should make efforts to engage employees so that they can identify with the organisation and thus become brand champions who "live the brand". In turn, additional research reveals managers need to implement brand-supportive behaviour that promotes a shared understanding of organisational brand values (e.g. Aurand et al. 2005; Punjaisri et al. 2008).

Accordingly, Liu et al. (2015, p. 319) outline internal branding as "an organization's attempts to persuade its staff to buy-in to the organization's brand value and transform it into a reality". Further, according to Foster et al. (2010), internal branding endeavours to certify that employees communicate the brand promise to customers at every service encounter (Foster et al. 2010). Recently, Saleem and Iglesias (2016) emphasise brand co-creation in internal branding, and argue that the aim of internal branding is to enable employee co-creation of brand value with various stakeholders.

Miller et al. (2014) propose that internal branding encourages both employees and managers to give their support to a new branding strategy (see also Hytti et al. 2015; Iyer et al. 2018). However, departing too much from what employees and other stakeholders have long regarded as core about the organisation, risks the danger of alienating them (Gotsi and Andriopoulos 2007).

With regard to mechanisms of internal branding, the roles of internal communication and human resource practices have been highlighted (Punjaisri et al. 2008). Internal communication advocates using two-way communications, comprising both formal and informal exchanges between employees and managers (Dean et al. 2016). It may include activities, such as, employee newsletters, memos sent by human resource management departments, employee storytelling and videos with messaging demonstrating a brand, for example 
(MacLaverty et al. 2007; Saleem and Iglesias 2016). According to Punjaisri et al. (2008) the prevailing research of human resource management in relation to internal marketing focuses particularly on recruiting, training, and compensating. Training, for example, may include activities such as: explanation of brand attributes and roles, brand workshops and brand tool kits, for example (MacLaverty et al. 2007).

Today, internal branding activities should be regarded as being as crucial as external ones in communicating brand promise to customers. Managers should carefully consider alignment of external and internal communication (Punjaisri and Wilson 2011).

\section{University branding}

Intensifying competition has increased the importance of branding in academia. Universities may, for example, wish to increase the number and quality of students (Belanger et al. 2002; Suomi 2014), improve student loyalty (Helgesen and Nesset 2007), improve alumni links (Ressler and Abratt 2009), recruit talented employees (Whisman 2009), and gain support from the corporate sector (Baker et al. 2005) as well as further distinguish themselves from other actors in higher education (Scarborough 2007). However, it is argued that higher education is distinctly multifaceted with regard to its stakeholder environment, and thus differs from many other environments (Chapleo and Simms 2010).

According to Dean et al. (2016, p. 3041) "the complex nature of higher education highlights the role of marketing and the internal market in realizing the brand identity, creating a challenge for developing a shared brand meaning". Indeed, the complexity of higher education as a service has been described in prior literature in terms of special characteristics of the higher education market, for example, high-perceived risks and long-term consequences for customers (Hemsley-Brown and Oplatka 2006; Ng and Forbes 2009). Thus, traditional branding approaches are not wholly applicable in the university context (Whisman 2009) and in order to be successful, universities should pay particular attention to factors such as internal brand management (Chapleo 2010). For example, higher education is a field in which branding efforts may be difficult because of great internal resistance (W raas and Solbakk 2009; Whisman 2009). Further, the multiple sub-brands and the complex brand architecture seem to hinder effective internal branding (Hemsley-Brown and Goonawardana 2007; Chapleo 2009), particularly for multi-campus universities with regional centres (Suomi et al. 2013a, 2013b; Suomi 2014), and for university mergers aimed at growing efficiency (Suomi 2015; Kallio \& Kallio 2014).

Particular difficulties arise in relation to internal branding in higher education organisations, in terms of distinct departments and units and manifold identities (Wæraas and Solbakk 2009). It is apparent, therefore, that the role of internal branding as part of brand management strategy is poorly understood in the higher education context, especially in relation to a significant rebranding programme, and this paper therefore contributes to knowledge in this area.

\section{Methodology}

A qualitative case study was employed to understand the effectiveness of internal branding "in depth and detail, holistically, and in context" (Patton 2002, p. 55). The study is considered an instrumental case study, as the case university's internal branding is examined mainly to offer insight into issues of internal branding in the university context (Stake 2005). Gummesson (2000) maintains that case studies may have specific value in applied social sciences as they provide practitioners with tools. 
Further, single-case design has been considered beneficial as it allows deeper understanding of the phenomenon under study (Gustafsson 2017) and is particularly useful when examining a complex and content-specific topic (Halinen and Törnroos 2005).

This research was conducted at a Canadian University of c25,000 enrolled students, during the fall of 2016, approximately 6 months after the university brand relaunch occurred.

\section{Background to the case}

This public institution is one of eleven universities in the province of British Columbia and one of ninety-eight universities in Canada. Established in the early 1970's, this institution was previously a community college but was assigned university status in the mid 2000s. As it moved from a teaching- to a research-focus, its culture evolved .

This university has a very broad mission supports learners of all abilities, through programmes in ESL (English as a second language) to graduate studies and academic research. Its educational provision bridges a wide range of disciplines including trades, business, arts and sciences, nursing, culinary arts, and law. The university also offers education both on campus and across the world through a range of online courses.

Approximately 25,000 students are enrolled at the university with around $85 \%$ of domestic Canadian origin. However, recently conducted research indicated that less than $5 \%$ of those surveyed outside the catchment area - primarily Alberta and British Columbia - had even heard of this institution.

The need to re-evaluate the organisational brand was driven by likely reductions in the numbers potential students expected within the region, increasing levels of competition from current and new players in the online education market, and the need to compensate for reduced public funds. The need to develop what this university refers to as a "strong and compelling brand" was therefore becoming urgent. The university's leadership felt that they needed a brand that inspires students to choose and commit to the university.

\section{Data collection method}

Semi-structured interviews were regarded as a suitable method for the data collection, as complex and ambiguous phenomena were studied (Gummesson 2005). All interviews were conducted by phone and ranged between 30 and $45 \mathrm{~min}$ in length. Interviews were conducted by telephone as some interviewees were located in distant locations, such as regional centres. It has been suggested that phone interviews can be used successfully in qualitative research and results should not differ from those conducted face-to-face (Sturges and Hanrahan 2004). In order to provide consistency, all the interviews were conducted by phone.

In keeping with the acknowledgement it is incumbent on researchers to begin with "the most obvious places and the most likely informants". (Corbin and Strauss 1990; Goulding 2002), research data for this study is based on interviews with specific mid-level administrators and deans including those at the student union, regional campuses, directors of departments, as well as deans of individual faculties and schools.

\section{Sampling}

In total, data from nineteen semi-structured interviews provide the data for this study. These nineteen interviewees were selected as they are a representative sample of this level of administration at the 
case university. Ultimately, purposeful sampling was conducted to cover informants who were considered relevant and information-rich (e.g., Carson et al. 2001) to this study. This research study has achieved theoretical saturation as no new themes beyond those identified arose; specifically, there was consistency in the variety of responses across the 19 interviews. In particular, from the seven directors at regional centres, four Regional Directors were interviewed; from the fifteen Directors of functional departments (including the President of the Student Union), five were interviewed; and of the twelve Deans of Faculties and Schools, eight were interviewed for this study.

\section{Interview themes}

The interview protocol (Appendix) was designed by reviewing prior literature on internal branding and university branding where key factors suggested to influence and impact upon the branding process were drawn out. The question schedule was then mapped back to the literature and checked by an independent researcher to ensure construct validity (Yin 2003), although the researchers were mindful to allow questions that were broad enough to allow rich narrative and insights to emerge, in keeping with the overall research purpose .

Particular themes focused around:

- levels of awareness and knowledge of the value of higher education branding;

- level of engagement, and support of the brand campaign;

- macro factors affecting the brand launch and campaign;

- influence of the brand campaign on organizational dept. systems and structures

All the interviews were recorded and transcribed to ensure the accuracy of the analysis and enhance the reliability of the study (e.g., Patton 2002), and to be able to present direct extracts from the data. And, although the interview guide was followed, interviewees were able to expand upon topics, resulting richer information, demonstrated through quotes. (Daymon and Holloway 2002).

\section{Analysis}

Transcripts were analysed using Nvivo qualitative data analysis software by an independent research assistant to minimise bias (e.g., Patton 2002). Thorough transcription and coded content analysis by NVivo was conducted. In the analysis, responses that illustrated semantic similarity were attached to one of the themes derived from the data (Miles and Huberman 1994). An independent researcher was used to code data initially. Doing so aided the authors to concentrate on thematic structures Open coding of key phrases was initially carried out followed by more topic specific sub-coding (King and Horrocks 2010).

\section{Findings}

Through the analysis of the data, a number of insights and themes became apparent:

\section{Understanding of higher education branding}

Overall there seemed to be a good understanding of the benefits of internal branding among interviewees, and a fairly positive view around branding overall. However, the articulation of benefits varied widely in terms of specifics, as is discussed below. 
First, some respondents perceived that the practice of branding was not really new and that historically colleges had "distinctive identities based on the scholars associated with them ... so, in that sense, trying to create a unique identity for an institution is a long-standing practice".

All interviewees were able to articulate some benefits, but a notable aspect was the great variance in views on the specific outcomes of external branding. The thread that did link almost all responses was a primary focus on prioritising the student recruitment role, and an ability to identify benefits linked to this, perhaps evident of a continuing narrow understanding of what internal branding is and can achieve.

A small number had a rather simplistic view of what branding could achieve, exemplified by views such as "basically, they're trying to attract consumers just like any organisation". These respondents suggested that work to fully embed a wider understanding of internal and external branding among staff is an ongoing task.

\section{Influence of internal branding activities on attitudes toward the new brand}

Broadly, most people did not believe that internal communications and activities changed their attitudes or their knowledge of how the institution's new brand may affect their roles. This may be partly attributed to a lack of understanding of the holistic view of the brand, and some negative views were evident with statements such as "the fact that we used a particular font and colour of yellow......does that have any impact on students? In my opinion.....zero". Educating internal audiences about how the rebrand may influence changes to the expected behaviour of deans and mid-level administrators is an ongoing task and a specific purpose of internal communications.

It was felt by some that newer staff "will embrace this much more strongly than some of our more senior staff because they haven't gone through all the iterations that have been in X". Indeed, there was a belief that change will take time as "in a couple of years it will begin to make an impact and "if the brand becomes part of what we do, how we act, how we behaveif we live up to the brand - then I think it may indeed help us attract and keep students".

Similarly, there was a degree of institutional fatigue towards the rebranding process among some longer term employees. This was clearly evident in quotes such as "I kinda [sic] don't pay attention anymore to tell you the truth. I've gone through name changes and where it's been wholesale, started from scratch again.... we had probably two or three different brands" or "ambivalent, not really knowing if this is what we need or not. I think we're all pretty disconnected from the whole exercise and how it materialised and now what it represents".

\section{Engagement with new brand}

In contrast to the previous point, a generally positive response to exploration of what the brand means to respondents was evident, with one respondent stating that "I do believe that the message accurately captures some important things" and a sense of progress was evident with the "furthest I've seen us come as an institution with trying to understand itself, identify, and communicate itself".

The positive awareness of what the institution's new brand could offer was encapsulated well by the view that "it creates a narrative...it's more about culture ... the narrative on the thing that you deliver and make real for students".

This sense of 'common purpose' was also suggested as what the brand means (to respondents) because "it's about telling the 70 people who are required to make that experience really 
good that you are connected to a common fabric that is important for this student to be able to do this".

Similarly, one respondent exemplified these positive perspectives among university staff by adding "that's what I think part of the branding process was to do - to bring people together to understand how all of us work as an institution." Those interviewed believe the new brand is a suitable fit for the institution; the challenge is to embed this view formally through the internal branding process.

\section{Levels of awareness, participation and support of the higher education rebrand planning, launch and campaign}

\section{Awareness}

All those interviewed were aware of the institution's rebranding campaign. Awareness (at a basic level) of the internally focused communications and activities supporting the rebrand planning and consultation process was also high.

\section{Participation}

The variation of views about topics such as participation and support on this answer was insightful.

To help create high levels of awareness, a significant number of respondents suggested that 'Town Hall meetings' were effective communication platforms because they allowed all views a forum and therefore created understanding.

Communication at this institution was generally seen with quite good as some respondents were "content with the amount of communication that came out about it". It seems that despite earlier talk of misunderstanding, a sincere attempt by Marketing and Communications to engage was welcomed as evidenced by the view that one respondent "got a call from [V.P. Marketing and Communications] ....making sure that I was involved and also that my campus and regional centres were involved, and they were very good about that, actually".

\section{Support}

In terms of internal support for the institution's rebranding process, there was also some cynicism evident among a significant proportion of those interviewed. Sometimes criticisms were overt, but at other times this view came out during probing, such as the view of one respondent who considered much of the internal communications and activities to be an exercise in limiting resistance at an early stage, and that consultations were "largely for political reasons-because they didn't want opposition from the [stakeholder group] when they launched the brand". Similarly the opinion that that the approach was "less about content and more about them generally saying if we were to go in this direction, would we have any opposition from you politically?" was voiced.

For others in the sample, it seemed that the process encouraged the adoption of a pragmatic view, such as that of a dean who stated that "I have to work with what I'm given at the university context... unless it's a total antipathy to my values, I really don't have an option but to be engaged". 


\section{Value of process}

Finally, there was evidence of a lack of appreciation among approximately half of respondents for the real value of the internal branding consultation, which is closely related to the above point about cynicism. This resulted in several respondents not prioritising or attending the meetings. A realistic view may be that it is inherently difficult to get all to engage, and this resistance is exemplified by statements such as "So, yes, I've been aware... and pretty well-briefed on what was going on as things were proceeding. On the other hand, I wasn't directly involved in any of the real work going on in the background". The somewhat cynical view that the process was an exercise in generating superficial 'buy in' and only an exercise without genuine value was a concern, and voiced to some degree by a small number of interviewees.

Therefore, although internal branding activities successfully raised the awareness about the institution's rebranding process and rebranding campaign, overall levels of internal support for this initiative were not wholly positive.

\section{Engagement with the internal rebranding committee}

There was some negativity associated with the internal communications and activities of the rebranding process itself. Indeed, despite efforts by Marketing and Communications to encourage engagement in the process, the feeling that "I did not like how some aspects of that exercise were imposed on us, and I didn't think it was done very professionally" was mentioned. As ever there was some criticism of the process, with advice that input was needed "not just input from faculty, but participation from faculty and staff and community and students".

Responses reveal that despite efforts to overcome (or at least mitigate) a cynicism persists around how the whole process of branding was conducted. This was evident through terminology such as "they (staff) don't believe they're being heard. They believe it's an exercise and the outcome has already been determined". Similar narrative was evident among several respondents and it seems that a key challenge is to reassure staff that their views are heard, and to be aware and address this cynicism.

It was interesting that there was some agreement between cynical responses and limited understanding of the role and value of branding among respondents. It was therefore suggested that initially instilling clear reasons why the rebrand was needed limited the need for the subsequent consultation process. Overall, participants who felt that engagement with the internal communications and rebranding process had positively influenced their levels of support also claimed to understand branding and its purpose, suggesting the value of engaging with and educating this level of administration early in the internal rebrand planning process.

Also, this brings to light questions about what is the best way to communicate with this stakeholder group. Several respondents stated that face to face meetings were generally preferred, and even consultation where "they could have sat down with me and my team and asked us directly what our experiences were with students out there?"

Consistent and ongoing communication was suggested as important; sporadic communication was viewed as a negative as "there's a lot more than dropping in once every five years when you do your strategic priorities, right?" 


\section{Challenges to the success of internal branding}

Overall, it was evident that the timing of the rebrand campaign did affect its level of success internally. This is particularly true in terms of events that were significant but perhaps difficult to anticipate (internal 'labour relations' issues, a federal election, and budgetary issues).

The culture of higher education was evident as part of this theme as "we're a bunch of smart people who all think they know the best way to do things". One specific concern was a lack of confidence in the robustness of data used to support branding decisions; awareness of providing information on provenance of decision data is evidently important. Overall, a deep seated academic cynicism was evident among some, which could be described as almost a suspicion of marketing activities.

A related emergent theme was that of 'distractions' that hindered the branding campaign. Principal among these was the controversy and arguable misconceptions around the phrase "Unearth Your Potential" used in promotional campaigns (some perceived that this had associations with a mining heritage that is regionally contentious) which received press coverage and detracted from the primary narrative and focus around the rebrand. This was unfortunate, and some respondents felt that it could have been anticipated and handled slightly differently as it caused some to "disengage with the whole process".

It was also unfortunate that the institution's rebrand launch coincided with a period of difficult industrial relations was characterized "a lot of cynicism about this launch because of what was going on in the university environment". It was suggested that the above issue impacted 'buy in', because "for the campaign to launch really successfully it needed faculty and staff buy-in, and they were in the middle of collective bargaining when they were intending to launch it". This, it was argued, obstructed the "sense of occasion and overall impact" and ultimately on "buy in".

Budgetary issues were not as widely cited, but one respondent argued that they "were being told that they couldn't have the resources that they needed to do a lot of things that they needed to do, and that's us deans and directors also. You know, we spent $250 \mathrm{~K}$ on a branding process. So it was really hard to keep faculty motivated".

\section{Centralising of marketing communications}

This institution's rebrand also involved centralizing many functions of marketing communications. Previously, individual departments and schools were able to operate relatively autonomously. This research also explored the attitudes of this stakeholder group towards centralizing marketing communications functions. In terms of volume of responses this was the largest area of questioning and of great potential interest for a discussion focusing on appropriate internal management approaches to the operational changes of the institutions marketing practices.

In terms of the challenges of implementation of brand architecture, it was argued that the "university brand is definitely the centralised message....so whilst the brand is centralised the recruitment activities have to be decentralised". It is, however, debatable whether this flexible brand architecture is in place in many institutions. These challenges range from structural challenges such as the "pervasive inclination of faculties to operate as separate entities" to simply the consistency of brand colours (there was a frequent focus on this).

For most respondents autonomous marketing communications within the schools and departments were preferred. Concerns in this area largely revolved around control. One expressed view focused on 
"pretty extensive promotional activities" that are no longer controlled by the individual schools and departments. The objection raised was that the marketing department did not have sufficient knowledge to answer specific department (or school) related questions from potential students. This concern was emphasized by one interviewee who wondered whether the Marketing and Communications department, now the first point of contact for student inquiries, has the resources to actually deliver 'what we promise'?

Forming an ideal brand architecture is seemingly still a challenge and the sense of perceived imposition of brand among several respondents also a significant negative; they argued that it should be confined to more visual aspects, as "I would like to see it confined more to identifying a visual brand and leaving the identity and personality of the university and its way of being to its teachers and its administrators and its students and let that come out in a more natural way".

\section{Benefits of centralisation}

Despite the above themes emerging, the benefits of centralisation of marketing were also widely recognised. For example, the increased resources available to a centralized Marketing and Communications department were understood and many welcomed the additional support of centralised marketing.

It certainly seems that before the rebranding and changes to Marketing and Communications systems, there was a sense of fragmentation and strong identification with the institution's department and school's sub brands, and opinions divided on the challenges involved with subsuming the individual department sub brands into the overall institution's brand. For example, these changes to the institution's systems served to increase the awareness of the importance of brand consistency. One respondent articulated this view as "I think now the department is very conscious...about any communication pieces, either visually or web or any communication."

Ultimately, most respondents acknowledge some internal benefits of centralisation and a move to a more consistent brand. There did seem to be the sense that most people were happy with the brand and one respondent saw it as a "cleaner" brand that "helps us communicate in a cleaner way", but that operationally difficulties were anticipated in terms of "compliance".

\section{Successful internal branding practices}

In the interests of best practice, respondents were asked to identify what they considered successful internal branding practices.

\section{Internal engagement}

A starting point in this area of our analysis is to highlight that respondents broadly thought that the internal engagement process and consultation stage of the rebranding process was important to the success of the rebranding campaign. Most initially spoke of the more tactical aspects of this activity, but a strategic approach with a "client-relationship management tool, because we wanted to make sure that all of the communications were properly branded and had consistent tone" was also evident.

\section{Launch event}

Most respondents cited examples that they felt had worked, such as well-located banners and other promotional materials, but several felt that "most memorable or effective was the launch event itself"; seemingly a launch event is important. 


\section{Consultation}

The theme of consultation recurred often, but the difficulty of actually achieving acceptable levels of consultation is again apparent with views that the "framework for contribution was perhaps a little bit naïve" illustrating this. Respondents talked of being critical of the approach without explaining quite how it could be enhanced. Some did offer specific advice though, to ensure that all are consulted (as it was felt by some that regions were "an afterthought"). This may be the central and most challenging of all aspects, as the view that "one thing that I would advise other institutions to do would be to consult" demonstrates.

\section{Awareness among managers}

It was apparent that it is necessary to ensure that this level of administration is aware of the benefits of a new brand to "build a consensus for the need to do a rebranding exercise, before you start the rebranding exercise". Management "need to show a good reason to undertake the rebrand" and respondents "need to be convinced that branding does play a role".

\section{Sustained launch}

The need for a "sustained launch" was discussed, as after launch:

"the flame burns really hot for a very short period, and then it's like the light's turned off, and it would be really good to sustain the hype.... So rather than just one event pushing how incredible the brand is...you draw it out into a longer thing with a number of events that give people a reminder of the brand so it becomes more and more entrenched".

Some measures to help build acceptance were also identified through this research. Primary among these was "a good explicit methodology" as you are "dealing with researchers and scholars. Create a methodology that would actually stand up to scrutiny". It was also argued that, particularly if those driving the branding agenda are new to the institution, account of the institutional history has to be considered to avoid alienation.

\section{Consultation}

Consultation was discussed and thought by some to be good, with views that

"the one thing that I think that was done and I would advise other institutions to do would be to consult. For some people, there will never be enough consultation, but I think that it's important to have kept people up-to-date on what's going on, why things are being done and so on. So, I think that was mostly done and it was mostly good and I would certainly recommend that to any other institution".

It was conceded that consensus is always hard to build in higher education institutions, but testing ideas and concepts was agreed as important.

A last interesting piece of advice to temper the discussion around the importance of consultation was "don't get caught up on this dragging out of a process to make everybody happy, because it's never going to happen, so sometimes you just have to forge ahead." This might seem contradictory but another respondent suggested that "you have to remember that these are the experts in the field and they can't weigh everyone else's opinion as equally as their own". 


\section{Discussion}

In keeping with the research objectives of this paper, discussion focuses on results in the following areas:

\section{The extent to which internal branding activities contribute to awareness and engagement with a new university brand}

The results of our study indicate that work is necessary to fully embed a wider understanding of branding among this level of administration. Educating the internal audience on the value of higher education branding is an important and ongoing task. Indeed, educating employees about the brand promise has been regarded as a key ambition of internal branding by definition (Punjaisri et al. 2009). In the university context, this is particularly emphasised because of the faculty members' typically personal and long contact with students (Woodall et al. 2014) and the strong influence on students' experience on university brands (Yu et al. 2016). Identification with the brand results in students becoming "brand supporters" and "brand owners" (Balmer and Liao 2007).

Additionally, this research suggests that internal branding should be ongoing in order to ensure that employees continue to communicate the desired brand identity through their behaviour and become "brand ambassadors" (Ind 2001; Whisman 2009; Yu et al. 2016).

This research reinforces the importance of clear communications from Marketing and Communications about how the rebrand affects the deans and administrators. Indeed, clear and integrated marketing communication has been acknowledged as critical component in an organization's brand strategy (Madhavaram et al. 2005). Specifically, Marketing and Communications may be able to outline specific changes that deans and mid-level administrators should take into consideration within their departments to ensure the new brand values are reflected in their day-to-day operational activities.

\section{Challenges in engaging internal stakeholders with a new university brand}

In this study, it seems that those interviewed do have a degree of 'buy in' to the institution's brand, and the challenge is to further embed that formally through the internal branding process and subsequently to the way deans and mid-level administrators support the new brand values.

With this in mind, it is of concern that some consider that the internal communications and engagement process used for the institution's rebrand is an exercise in generating superficial 'buy in' without genuine value. Although the most cynical views were expressed by a minority of the interviewees, it is important to pay attention to these critical voices, in order to lessen possible dissent and give opportunities to contribute to brand building (see also Yu et al. 2016), and thus better engage them in the process.

This study found that the sense of imposition of the institution's brand among several respondents from different departments is a significant negative; in short it seems it is very hard to build 'buy in' to one overall institutional brand. This observation compliments findings of Chapleo (2009) who reported on schools and faculties seeking to build a distinct reputation. Furthermore, Hemsley-Brown and Goonawardana (2007) note that in the worst case, without brand harmonisation, individual schools or faculty branding may even damage the entire university brand. 
Specifically, at this institution, it seems that before the programme there was a sense of internal fragmentation, amounting to continuing identification with individual school and department sub brands, which is a common issue in building one consistent brand identity at the university level (e.g., Hemsley-Brown and Goonawardana 2007; Chapleo 2009). Most, however, acknowledge the benefit of centralised brand management activities in mitigating this negative outcome. This study therefore also supports Miller et al.'s (2014) study of the importance for internal communication to boost employee support of a new organizational branding strategy.

\section{Beneficial practices in promoting a new university brand internally}

Consideration of opinions of the respondents in the context of the literature allows the identification of a number of areas, which, whilst they do not necessarily constitute 'best practice', certainly offer insights for those undertaking internal branding programs. This paper has suggested the need to build a case for a rebranding exercise before you start the rebranding exercise, as scholars have reported strong internal resistance and cynicism towards branding efforts (Whisman 2009; W raas and Solbakk 2009; Chapleo 2010), even in terms of parodying the branding campaign of the university (Aspara et al. 2014). In this case study, it seems Marketing and Communications missed an opportunity to clearly build a case for why they needed to rebrand.

In keeping with this above mentioned theme, measures to help build acceptance were suggested; key advice given to other higher education institutions was to consult. Seemingly, the value of receiving on-going feedback and input from the regions where the institution has several campuses is key. It is important to bear this in mind as multi-campus universities with regional centres have been regarded as particularly challenging in terms of building a consistent brand identity at university level (Suomi et al. 2013a, b; Suomi 2014).

However, a robust view was that after consulting you must move on to implement, as ultimately it is marketing professionals who drive the process. As the example of the initially suggested slogan "Unearth Your Potential" shows, it would be useful to test visual imagery and slogans amongst relevant stakeholders before the actual launch, in order to check interpretations and ensure that the brand identity concept is comprehensible and appealing (Burmann and Zeplin 2005, p. 288; Aspara et al. 2014).

Additionally, this research has revealed the importance of providing information on provenance of data used to support decisions; this is probably more important in the context of higher education than in many other sectors, as employees typically have a substantial degree of freedom (W raas and Solbakk 2009), and higher education institutions are reliant on knowledge workers and their expertise (LØwendahl 2005).

\section{Limitations of the study and future research}

It may be considered a limitation for the study that it is based on one case university in one country. However, the value of single-case design is in comprehensive and intensive examination, thus adding more cases might have provided a broader sample but 'thinner' picture of the phenomenon under study. Single-case design allows analytical generalization to other similar contexts (e.g., Dubois and Gadde 2002). The higher education context of this study represents a knowledge-intensive organization where knowledge-workers typically enjoy a high degree of autonomy (Alvesson 2004), and thus organizational changes, such as rebranding under one unified brand, may face strong internal resistance (e.g., Aspara et al. 2014). Therefore, the value of this comprehensive and intensified single-case study design is in 
its analytical referenceability (e.g., Dubois and Gadde 2002) for similar future higher education and large institutional re-branding research studies, with potential applicability to other large public sector organizations, where similar underpinnings of brand management and its challenges have been found in these contexts (e.g., Wæraas 2008; Wæraas and Solbakk 2009).

As a case study, this paper has revealed a number of areas where future research could add significant value. In particular, as this work looks at elements of internal re-branding management communication practices around the time of an institutional rebrand, it has identified the opportunity to measure the long-term impact of a university's rebranding process through an on-going study. Specifically, future research could explore middle and longer term attitudinal and operational characteristics of re-branding success among this key stakeholder group. Future longitudinal research on this topic could also explore the internal operational and attitudinal impacts of the internal branding process on the affected stakeholders.

The identified sample of middle managers and administrators was considered appropriate as they are the most likely informants who help shape the agenda and narrative, and often act as communication conduits (Goulding 2002), but it is conceded that the wider employees have a key role in the rebrand, particularly in terms of implementation, and future work that looks at this may be valuable.

Additionally, future research could contribute to this topic through exploring specific communication types, and their effectiveness at engaging internal middle management and department deans. For example, although this research has revealed the effectiveness of events and activities, such the rebrand launch event, more exploration of the effectiveness of additional particular communication types would be of value. Specifically, in light of the rise of digital marketing, exploring the effectiveness of various digital marketing campaigns on internal stakeholders would be of value.

Lastly, the extent to which this response resonates with the student population is also an opportunity for future research. This student-focused research could also be explored effectively through a longitudinal analysis.

\section{Conclusions}

Overall, this research reveals a number of significant factors that link to appropriate internal branding for higher education institutions:

Firstly, this research has revealed for a higher education institutional rebrand to be successful, it is necessary to ensure that mid-level administration and management are aware of the benefits of branding. By accomplishing this level of 'buy in', future cynicism and criticisms among this important stakeholder group may be mitigated. For example, if all members of this stakeholder group are explicitly educated about the positive benefits of establishing a strong institutional brand, there will be fewer questions regarding the use of university resources for this activity.

Secondly, this study reveals that, while a brand launch event was important, ongoing brand reinforcement and education is also valuable and necessary.

The findings also demonstrate the extent to which other external or internal institutional factors may influence the success of the university's internal rebranding planning process and campaign. In this case for example, the rebranding activities were negatively impacted by internal labour disputes, a federal election and contentious topics within the surrounding community.

In summary, this case study has revealed, that internal communications supporting institutional re-branding activities have a powerful and valuable role for an institution's re-brand strategy. 
Through focusing on the middle-management stakeholder group, this paper has added to the brand management literature and demonstrated theoretical and practical implications for improved understanding of higher education and large institutions re-branding planning and campaign.

Acknowledgements The third author wishes to thank Development Program of Knowledge-Intensive Economy (ASKO), The Regional Council of Satakunta and European Regional Development Fund (ERDF) for funding this study.

Funding Information Open access funding provided by University of Turku (UTU) including Turku University Central Hospital.

\section{Appendix: Interview protocol}

\section{Your level of Awareness and knowledge of the value of higher education branding?}

A. Do you support / agree with the idea of higher education branding? Why / Why not?

B. Are you aware of the expected benefits of higher education organization branding? Discuss some of the benefits to a University you are aware of.

\section{Your level of knowledge, Engagement, and support of the HE brand launch and campaign at $\mathrm{X}$ ?}

A. Are you aware of X's brand relaunch / focus?

B. How is the new $\mathrm{X}$ brand different from the previous $\mathrm{X}$ brand? For students? For faculty?

C. Have you been directly involved with any of the $\mathrm{X}$ branding committees planning and preparation for the new brand? For example, have you attended any of the town hall meetings, dept. information sessions, and round-tables?

D. Describe the extent of efforts made to communicate with you directly about the new brand positioning by the $\mathrm{X}$ marketing communications dept.? What has been the most memorable / effective method used?

E. How have the above efforts (involvement and knowledge of the $\mathrm{X}$ branding process, benefits of branding) influenced your $-/+$ support of the new branding campaign

\section{Macro Factors affecting the higher education brand launch and campaign}

A. Has the timing of this brand launch and campaign had any effects on the success of the brand launch?

B. Has any other issues / factors distracted / benefitted you from the success of this brand launch and campaign? Department factors? University factors? Community factors? Student factors?

C. What factors do you believe have most \pm affected this brand launch?

\section{Influence of the brand campaign on organizational dept. systems and structures?}

A. What, if anything, has changed in your dept. as a result of the new branding campaign at X? 
B. Do you feel the new brand has changed the decision-making processes related to the institutions marketing communications activities?

C. Do you believe the new brand affects you and your department? Explain?

D. Have any work processes, or systems, or personnel changed in your dept. due to the new branding at $\mathrm{X}$ ?

\section{Suggestions to improve a brand launch for other higher education / government organizations?}

A. Is more education about how the new $\mathrm{X}$ brand is different from its previous brand necessary?

B. Do you have any additional suggestions on how to improve the brand launch and campaign for other institutions? For X?

Open Access This article is distributed under the terms of the Creative Commons Attribution 4.0 International License (http://creativecommons.org/licenses/by/4.0/), which permits unrestricted use, distribution, and reproduction in any medium, provided you give appropriate credit to the original author(s) and the source, provide a link to the Creative Commons license, and indicate if changes were made.

\section{References}

Alvesson, M. (2004). Knowledge work and knowledge-intensive firms. New York: Oxford University Press.

Aspara, J., Aula, H.-M., Tienari, J., \& Tikkanen, H. (2014). Struggles in organizational attempts to adopt new branding logics: The case of a marketizing university. Consumption Markets \& Culture, 17(6), 522-552.

Aurand, T. W., Gorchels, L., \& Bishop, T. R. (2005). Human resource management's role in internal branding: An opportunity for cross-functional brand message synergy. Journal of Product \& Brand Management, 14(3), 163-169.

Baker, S. M., Faircloth, J. B., \& Simental, V. (2005). Perceptions of university-corporate partnership influences on a brand. Journal of Marketing Theory and Practice, 13(2), 32-46.

Balaji, M. S., Roy, S. K., \& Sadeque, S. (2016). Antecedents and consequences of university brand identification. Antecedents and consequences of university brand identification. Journal of Business Research, 69(8), 3023-3032.

Balmer, J. M. T., \& Liao, M.-N. (2007). Student corporate brand identification: an exploratory case study. Corporate Communications: An International Journal, 12(4), 356-375.

Belanger, C., Mount, J., \& Wilson, M. (2002). Institutional image and retention. Tertiary Education and Management, 8(3), 217-230.

Burmann, C., \& Zeplin, S. (2005). Building brand commitment: A behavioural approach to internal brand management. Journal of Brand Management, 12(4), 279-300.

Carson, D., Gilmore, A., Perry, C., \& Gronhaug, K. (2001). Qualitative marketing research. London: Sage Publications.

Chapleo, C. (2009). External perceptions of successful university brands. International Journal of Educational Advancement, 8(3), 126-135.

Chapleo, C. (2010). What defines 'successful' university brands? International Journal of Public Sector Management, 23(2), 169-183.

Chapleo, C., \& Clark, P. (2016). Branding a tertiary institution by committee: An exploration of internal brand analysis and management processes. Journal of Brand Management, 23(6), 631-647.

Chapleo, C., \& Simms, C. (2010). Stakeholder analysis in higher education: A case study of the University of Portsmouth. Perspectives: Policy and Practice in Higher Education, 14(1), 12-20.

Corbin, A., \& Strauss, J. M. (1990). Basics of qualitative research: Grounded theory procedures and techniques. Thousand Oaks: Sage Publications. 
Davies, G. (2008). Employer branding and its influence on managers. European Journal of Marketing, 4(5-6), $667-681$.

Daymon, C., \& Holloway, I. (2002). Qualitative research methods in public relations and marketing communications. London: Routledge.

de Chernatony, L. (2001). From brand vision to brand evaluation: Strategically building and sustaining brands (3rd ed.). Oxford: Butterworth-Heinemann.

de Chernatony, L., \& Dall'Olmo Riley, F. (1998). Modelling the components of the brand. European Journal of Marketing, 32(11-12), 1074-1090.

Dean, D., Arroy-Gamez, R. E., Punjaisri, K., \& Pich, C. (2016). Internal brand co-creation: The experiential brand meaning cycle in higher education. Journal of Business Research, 69(8), 3041-3048.

Dholakia, R. R., \& Acciardo, L. A. (2014). Branding a state university: Doing it right. Journal of Marketing for Higher Education, 24(1), 144-163.

Dubois, A., \& Gadde, L.-E. (2002). Systematic combining: An abductive approach to case research. Journal of Business Research, 55(7), 553-560.

Foster, C., Punjaisri, K., \& Cheng, R. (2010). Exploring the relationship between corporate, internal and employer branding. Journal of Product \& Brand Management, 19, 401-409.

Gotsi, M., \& Andriopoulos, C. (2007). Understanding the pitfalls in the corporate rebranding process. Corporate Communications: An International Journal, 12(4), 341-355.

Goulding, C. (2002). Grounded theory: A practical guide for management, business and market researchers. London: Sage.

Gummesson, E. (2000). Qualitative methods in management research (2nd ed.). Thousand Oaks, CA: Sage Publications.

Gummesson, E. (2005). Qualitative research in marketing. Road-map for a wilderness of complexity and unpredictability. European Journal of Marketing, 39(3-4), 309-327.

Gustafsson, J. (2017). Single case studies vs. multiple case studies: A comparative study. <https://www. semanticscholar.org/paper/Single-case-studies-vs-.-multiple-case-studies-\%3A-A-Gustafsson/ae1 f06652379 a8cd56654096815dae801a59cba3> retrieved 25th June 2018.

Halinen, A., \& Törnroos, J.-A. (2005). Using case methods in the study of contemporary business networks. Journal of Business Research, 58(9), 1285-1297.

Helgesen, Ø., \& Nesset, E. (2007). Images, satisfaction and antecedents: Drivers of student loyalty? A case study of a Norwegian university college. Corporate Reputation Review, 10(1), 39-59.

Hemsley-Brown, J., \& Goonawardana, S. (2007). Brand harmonization in the international higher education market. Journal of Business Research, 60(9), 942-948.

Hemsley-Brown, J., \& Oplatka, I. (2006). Universities in a competitive global marketplace: A systematic review of the literature on higher education marketing. International Journal of Public Sector Management, 19(4), 316-338.

Hytti, U., Kuoppakangas, P., Suomi, K., Chapleo, C., \& Giovanardi, M. (2015). Challenges in delivering brand promise - Focusing on municipal health care organisations. International Journal of Public Sector Management, 28(3), 254-272.

Ind, N. (2001). Living the brand. How to transform every member of your organization into a brand champion (3rd ed.). London: Kogan Page.

Iyer, P., Davari, A., \& Paswan, A. (2018). Determinants of brand performance: The role of internal branding. Journal of Brand Management, 25(3), 202-216.

Kallio, K-M. \& Kallio, T. J. (2014). Management-by-results and performance measurement in universities Implications for work motivation. Studies in Higher Education, 39(4), 574-589.

King, N., \& Horrocks, C. (2010). Interviews in qualitative research. London: Sage.

Kuoppakangas, P., Suomi, K., Clark, P. Chapleo, C. \& Stenvall, J. (2019) Dilemmas in re-branding a university - "maybe people just don't like change": Linking meaningfulness and mutuality into the reconciliation" Corporate Reputation Review. doi: https://doi.org/10.1057/s41299-019-00080-2.

Liu, G., Chapleo, C., Ko, W. W., \& Ngugi, I. K. (2015). The role of internal branding in nonprofit Brand Management: An empirical investigation. Nonprofit and Voluntary Sector Quarterly, 44(2), 319-339.

Løwendahl, B. (2005). Strategic Management of Professional Service Firms. Copenhagen: Copenhagen Business School Press.

MacLaverty, N., McQuillan, P. \& Oddie, H. (2007). Internal branding best practices study. Canadian Marketing Association.

Madhavaram, S., Badrinarayanan, V., \& McDonald, R. E. (2005). Integrated marketing communications (IMC) and brand identity as critical components of brand equity strategy: A conceptual framework and research propositions. Journal of Advertising, 34(4), 69-80.

Melewar, T. C., \& Nguyen, B. (2014). Five areas to advance branding theory and practice. Journal of Brand Management, 21(9), 758-769. 
Miles, M. B., \& Huberman, A. M. (1994). Qualitative data analysis: An expanded sourcebook. Thousand Oaks: Sage Publications.

Miller, D., Merrilees, B., \& Yakimova, R. (2014). Corporate rebranding: An integrative review of major enablers and barriers to the rebranding process. International Journal of Management Reviews, 16(3), 265-289.

Ng, I. C. L., \& Forbes, J. (2009). Education as service: The understanding of a university experience through the service logic. Journal of Marketing for Higher Education, 19(1), 38-64.

Patton, M. Q. (2002). Qualitative research \& evaluation methods (3rd ed.). Thousand Oaks, CA: Sage Publications.

Punjaisri, K., \& Wilson, A. (2011). Internal branding process: Key mechanisms, outcomes and moderating factors. European Journal of Marketing, 45(9-10), 1521-1537.

Punjaisri, K., Wilson, A., \& Evanschitzky, H. (2008). Exploring the influences of internal branding on employees' brand promise delivery: Implications for strengthening customer-brand relationships. Journal of Relationship Marketing, 7(4), 407-424.

Punjaisri, K., Wilson, A., \& Evanschitzky, H. (2009). Internal branding to influence employees' brand promise delivery: A case study in Thailand. Journal of Service Management, 20(5), 561-579.

Rafiq, M., \& Ahmed, P. K. (1993). The scope of internal marketing: Defining the boundary between marketing and human resource management. Journal of Marketing Management, 9(3), 219-232.

Ressler, J., \& Abratt, R. (2009). Assessing the impact of university reputation on stakeholder intentions. Journal of General Management, 35(1), 35-45.

Saleem, F. Z., \& Iglesias, O. (2016). Mapping the domain of the fragmented field of internal branding. Journal of Product \& Brand Management, 25(1), 43-57.

Scarborough, E. (2007). The branding of higher education: The great awakening in the hallowed halls of academia. Simpson Scarborough. Intelligent marketing for higher education, http://magazine.austincollege. edu/fall09/webxtras/Branding_HallowedHalls_Scarborough.pdf, accessed 17 June 2017.

Simmons, J. A. (2009). Both sides now': Aligning external and internal branding for a socially responsible era. Marketing Intelligence \& Planning, 27(5), 681-697.

Stake, R. E. (2005). Qualitative case studies. In N. K. Denzin \& Y. S. Lincoln (Eds.), Strategies of qualitative inquiry (3rd ed., pp. 119-150). Thousand Oaks: Sage Publications.

Sturges, J.E. \& Hanrahan, K. J. (2004). Comparing telephone and face-to-face qualitative interviewing: A research note. In Qualitative Research. SAGE Publications, 4(1), 107-118.

Sujchaphong, N., Nguyen, B., \& Melewar, T. C. (2014). Internal branding in universities and the lessons learnt from the past: The significance of employee brand support and transformational leadership. Journal of Marketing for Higher Education, 25(2), 204-237.

Sullivan, J. (2004). The 8 elements of a successful employment brand". ER Daily. http://www.ere.net/2004/02/23 /the-8-elements-of-a-successful-employment-brand.

Suomi, K. (2014). Exploring the dimensions of brand reputation in higher education - A case study of a Finnish master's degree programme. Journal of Higher Education Policy and Management, 36(6), 646-660.

Suomi, K. (2015). Managing brand identity and reputation - a case study from Finnish higher education. Doctoral thesis, publications of Turku School of Economics, series a, Juvenes Print, Turku, Finland.

Suomi, K., Lemmetyinen, A., \& Go, F. (2013a). The tension between a distinct brand identity and harmonisation - Findings from Finnish higher education. Place Branding and Public Diplomacy, 9(3), 202-215.

Suomi, K., Kuoppakangas, P., Hytti, U., Hampden-Turner, C., \& Kangaslahti, J. (2013b). Focusing on dilemmas challenging reputation management in higher education. International Journal of Educational Management, 28(4), 461-478.

Vallaster, C., \& de Chernatony, L. (2006). Internal brand building and structuration: The role of leadership. European Journal of Marketing, 40(7-8), 761-784.

Wæraas, A. (2008). Can public sector organizations be coherent corporate brands? Marketing Theory, 8(2), $205-221$.

Wæraas, A., \& Solbakk, M. N. (2009). Defining the essence of a university: Lessons from higher education branding. Higher Education, 57(4), 449-462.

Whisman, R. (2009). Internal branding: A university's most valuable intangible asset. Journal of Product and Brand Management, 18(5), 367-370.

Woodall, T., Hiller, A., \& Resnick, S. (2014). Making sense of higher education: Students as consumers and the value of the university experience. Studies in Higher Education, 39(1), 48-67.

Yin, R.K. (2003). Case study research. Design and methods. $8^{\text {th }}$ ed. Sage Publications, Newbury Park, CA.

Yu, Q., Asaad, Y., Yen, D. A., \& Gupta, S. (2016). IMO and internal branding outcomes: An employee perspective in UK HE. Studies in Higher Education, 43(1), 37-56.

Publisher's note Springer Nature remains neutral with regard to jurisdictional claims in published maps and institutional affiliations. 